\title{
ACID METABOLISM IN RHEUMATIC CHILDREN
}

BY

WILFRID W. PAYNE, M.B., B.S.

(From the Hospital for Sick Children, Great Ormond Street, London.)

Whatever theory of the aetiology of rheumatism which may be held it is impossible to avoid speculation concerning the nature of the diathesis which appears to be necessary for the acquiring of the disease. Foremost amongst such speculation is that which postulates an ' acid diathesis.' Much indirect evidence has been produced at various times but no direct evidence of such a diathesis is available. If such a diathesis be present and be capable of detection there should be a difference between the normal and the rheumatic child in the acid-base balance of the blood. In an otherwise normally functioning body this difference might well be beyond the capacity of ordinary methods to detect, as indeed is the case (Parsons ${ }^{1}$ ), owing to the efficiency of the excretory organs. Of these, the kidney is the most important and therefore an examination of the acid output might reveal differences impossible to detect in the blood.

Method,-The method adopted was to take a group of about 200 children attending a ' rheumatic clinic' and two control groups-one being another group attending an 'asthma clinic' and the third a group of healthy children. Unfortunately it was not possible to obtain as many as 200 healthy children from the hospital out-patients, so permision was sought to examine 200 children from a nearby school which would have given a reasonable control group drawn from a similar population under similar conditions. The authorities could not see their way to grant this permission but instead suggested one of the residential schools of Banstead, the inhabitants of which were drawn from the same strata of society and the same districts as the majority of out-patients. This group was, however, living under different conditions both of environment and diet. This point will be referred to later on. They were in normal health and children suffering from any complaint were excluded.

The urines in all three groups were collected in the same manner. Three labelled bottles containing 3 to 5 c.c. of toluene were supplied and instructions were given that on the day before the next attendance samples of the urine passed, (1) on rising, 
(2) after breakfast, and (3) on going to bed, should be collected and put into their respective bottles. The following examinations were then undertaken:-

Specific gravity, $\mathrm{pH}$ by means of indicators, free acid titrated to $\mathrm{pH} 7 \cdot 6$ with $\mathrm{N} / 10 \mathrm{NaOH}$, ammonia (formalin method), titration with $\mathrm{N} / 10 \mathrm{HCl}$ to free acid using methyl orange, chlorides (modified Claudius method), phosphate (Briggs) and urea (McLean). These methods are all of sufficient accuracy for the purpose but occasionally the ammonia titrations had to be discarded owing to ammoniacal decomposition.

The phosphate has been expressed as c.c. of $\mathrm{M} / 10$ phosphate solution per cent. As it can be assumed without great inaccuracy that between the $\mathrm{pH}$ range used in the titration of acid and alkali $(3-7 \cdot 6)$ phosphoric acid is monobasic, this figure gives the amount of $\mathrm{N} / 10$ acid which corresponds to the amount of phosphate in the urine. Thus since the sum of the acid and alkali titrations gives an approximate value for the total acids present the differences between this and phosphate will indicate the amount of acid which is not phosphate (i.e., bicarbonate and organic acids).

These methods of investigation have been used by many observers in attacking the problem of acid excretion. With few exceptions owing to the difficulties of obtaining the total urine passed, absolute values for acid excretions have not been available. The actual percentage values are subject to misleading variations owing to the large number of uncontrolled factors which can influence the total fluid excretion (e.g. fluid consumption, sweating, hot or cold, dry or wet atmosphere). The final values used therefore have been the titration value of acid, alkali and ammonia expressed as c.c. of $\mathrm{N} / 10$ solution per 100 c.c. of urine divided by the percentage of urea. In the case of the phosphate the values have been expressed as c.c. of tenth molar phosphate per 100 c.c. divided by the urea percentage.

Two other ratios have been used, ' $\mathbf{R}$ ' an ammonia/acid ratio which indicates how much acid has been neutralized by ammonia and ' $P$ ' a phosphorus/total free acid ratio which varies directly with the phosphate and inversely with the amount of organic acid present, the higher the ratio the less the organic acid. ' $\mathbf{R}$ ' was introduced by Henderson and Palmer ${ }^{2}$ (who, however, used acid/ammonia, which gives a figure which is nearly always less than 1). An increase in the value of ' $R$,' providing it is not due to decomposition of the urine, indicates an increased neutralization of free acid by ammonia. This ammonia is produced in the kidney (Benedict and $\mathrm{Nash}^{3}$ ) and helps in excreting the excess acid since there seems to be a limit, in children especially, to the amount of free acid that can be excreted.

Since the hydrogen ion concentration is relatively unaffected by dilution the $\mathrm{pH}$ value does not require to be corrected for adventitious changes in volume. However, it gives no indication of the amount of acid excreted and so cannot be considered by itself as a reliable index of the acid excretion.

Since diurnal variations occur, it is possible that differences might be apparent at one time of the day and not at another. For this reason the three specimens have all to be compared. Although examination of one specimen passed at a variable time after breakfast is not the best way to detect the existence of an alkaline tide some information can be obtained by a study of the changes brought about by breakfast. It is possible that if overmuch acid were being produced the alkaline tide would be less marked. 
The occurrence of an alkaline tide as indicated by the $\mathrm{pH}$, by the acid ratio and by ' $\mathbf{R}$ ' has therefore been estimated in each group (table 1 ).

TABLE 1.

INCIDENCE OF ' ALKaLine tide' (PERCentage Figures of EACh GROUP OF ChildRen).

\begin{tabular}{|c|c|c|c|}
\hline Method. & Normal. & Rheumatic. & Asthmatic. \\
\hline $\begin{array}{l}\text { pH 2nd spec. more alkaline } \\
\text { Acid /Urea }=\text { 'Free Acid' table }\end{array}$ & 55 & 67 & \\
\hline $\begin{array}{l}\text { Lower ratio in } 2 \text { nd spec. } \\
\text { Ammonia / Acid }={ }^{\circ} \mathbf{C}\end{array}$ & 69 & 76 & $81 \cdot 5$ \\
\hline Higher ratio in 2 nd spec. ... & 64 & 70 & 74 \\
\hline
\end{tabular}

It will be seen that the ' acid ratio' shows the presence of an alkaline tide in the greatest proportion of cases, closely followed by ' $\mathbf{R}$ ' whereas the $\mathrm{pH}$ gives the least. By all three methods the normal group presents an alkaline tide least frequently while in the two more sensitive methods the asthmatic group shows it most frequently.*

(a)

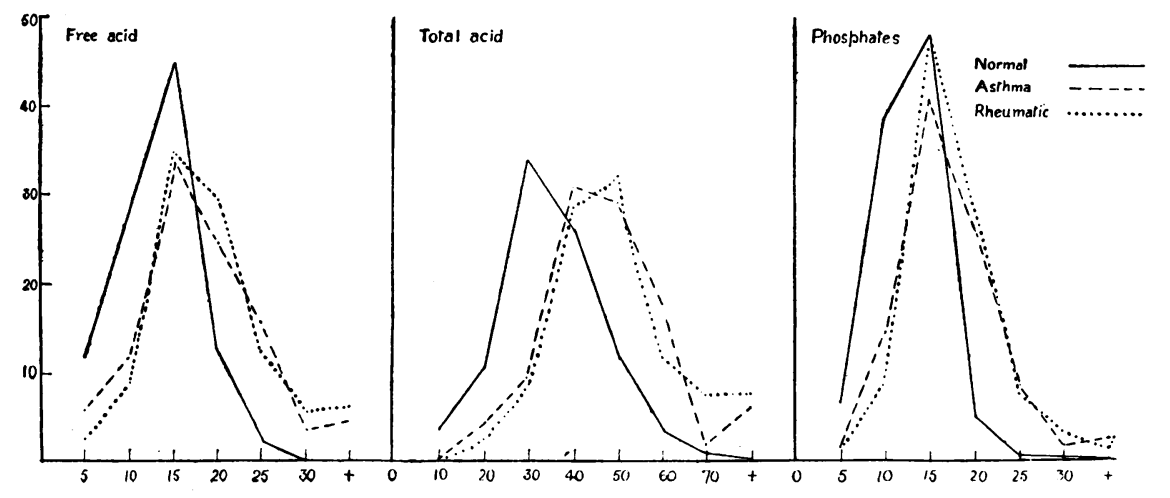

Fig. 1. (b)

The existence of the alkaline tide was first observed by Bence Jonesa who considered it to be due to withdrawal of acid from the blood for the purpose of
digestion. Roberts ${ }^{b}$ first entitled it the alkaline tide and considered it to be due to the alkaline nature of the meal and therefore to vary with the meal. While both noted the greater constancy of the alkaline tide after breakfast their observations were related to change of titratable acid after any meal. There has been a tendency to regard the alkaline tide as applying only to the alkaline tide following breakfast and even to ignore the necessity of a meal in its production. Garrattc, in 1904, cbndemned this and states that the change of reaction following awakening and resumption of activity was merely an ' acid ebb' from the acid night condition, not an active, alkaline tide. It is interesting to note that the same three ideas are still being debatedd.

a. Bence-Jones, H., Animal Chemistry, London, 1850, Lec. 5.

b. Roberts, W., Urinary and Renal Diseases, London, 1872, 48.

c. Garratt, G. C., Med. Chir. Trans., London, 1904, LXXXVII, 163.

d. Brunton, C. E., J. Physiol., Cambridge, 1933, LXXVIII, 65. 
In the succeeding tables an attempt has been made to summarize the acid, total acid, phosphate, $\mathrm{pH}, \mathbf{P}$, and non-phosphate acid, and ' $\mathbf{R}$ ' ratios. In fig. 1, $a, b$, c frequency curves of the results from the first specimens of the three groups have been plotted. Inspection of these shows that the asthma and rheumatic groups are almost alike and that both diverge from the normal. Inspection alone cannot determine the degree of significance of these differences and so the statistical method has been applied. The numbers available in each group while not large (about 200) are of sufficient magnitude to render the results of some significance. In any case there seemed no other available method of presenting the ten thousand results in an understandable form. Although in statistical terminology these results do not closely follow the ' normal' distribution it is considered that the standard deviation (S.D.) of the mean would be of sufficient accuracy for a survey of this nature. In calculating the 'S.D.' of the difference between the two means the method advocated by Fisher ${ }^{4}$ has been followed. A difference is deemed to be significant if it is more than twice the 'S.D.'

The standard deviation of the mean is a value which gives an indication of the probable differences of the means of a series of finite groups taken from an infinite 'population.' If two groups, e.g., asthmatic and normal, are in reality drawn from the same 'population' then the means will differ by more than twice the 'S.D.' only once in twenty tests. If the same means differ by a greater amount it may reasonably be assumed that the original populations are not identical in respect to the population under examination.

TABLE 2.

The standard deviation of the mean and the standard deviation of the values FOR FREE ACID.

\begin{tabular}{|c|c|c|c|c|c|c|c|c|c|}
\hline \multirow[b]{2}{*}{ Spec. } & \multicolumn{3}{|c|}{ Normal. } & \multicolumn{3}{|c|}{ Asthına. } & \multicolumn{3}{|c|}{ Rheumatism. } \\
\hline & Mean. & $\begin{array}{c}\text { S.D. } \\
\text { of mean. }\end{array}$ & S.D. & Mean. & $\begin{array}{c}\text { S.D. } \\
\text { of mean. }\end{array}$ & S.D. & Mean. & $\begin{array}{c}\text { S.D. } \\
\text { of mean. }\end{array}$ & S.D. \\
\hline 1. & $11 \cdot 3$ & .33 & 4.9 & $16 \cdot 0$ & .54 & $7 \cdot 1$ & 16.9 & .44 & $6 \cdot 5$ \\
\hline 2. & $7 \cdot 5$ & .31 & 4.9 & $10 \cdot 3$ & .53 & $7 \cdot 0$ & $10 \cdot 1$ & $\cdot 43$ & $6 \cdot 3$ \\
\hline 3. & $0 \cdot 1$ & .36 & $5 \cdot 3$ & $13 \cdot 1$ & .52 & 6.8 & $13 \cdot 0$ & $\cdot 50$ & $7 \cdot 3$ \\
\hline
\end{tabular}

In table 2 a third value-the standard deviation has been included. This value gives some indication of the spread of the individual results away from the mean, the smaller this value the closer the various values approximate to the mean. It will be seen that in all estimations this value is smaller in the normal group than in the other groups. Since many of the groups are far from normal in their distribution the 'S.D.' value is in these cases only a rough approximation, 
TABLE 3.

. MeAN Results FOR tOtAl ACID, ' R,' PH, PHOSPhate, NON-PhOSPHate aCid AND P.

\begin{tabular}{|c|c|c|c|}
\hline Spec. & Normal. & Asthma. & Rheumatism. \\
\hline \multicolumn{4}{|c|}{ Total Acid. } \\
\hline 1. & $31 \cdot 2 \pm \cdot 70$ & $42 \cdot 5 \pm 95$ & $44 \cdot 5 \pm .98$ \\
\hline 2. & $24 \cdot 8 \pm \cdot 65$ & $37 \cdot 8 \pm 1 \cdot 02$ & $32 \cdot 6 \pm 1 \cdot 0$ \\
\hline 3. & $25 \cdot 1 \pm \cdot 67$ & $35.6 \pm 1.05$ & $34 \cdot 9 \pm \cdot 93$ \\
\hline \multicolumn{4}{|c|}{ R. } \\
\hline 1. & $1 \cdot 85 \pm \cdot 039$ & $1.83 \pm \cdot 052$ & $1 \cdot 74 \pm \cdot 040$ \\
\hline 2. & $2 \cdot 33 \pm \cdot 046$ & $2 \cdot 31 \pm \cdot 058$ & $2 \cdot 33 \pm \cdot 052$ \\
\hline 3. & $2 \cdot 02 \pm \cdot 049$ & $1 \cdot 85 \pm \cdot 056$ & $1 \cdot 85 \pm \cdot 053$ \\
\hline \multicolumn{4}{|c|}{ pH. } \\
\hline 1. & $5 \cdot 72 \pm \cdot 043$ & $5 \cdot 75 \pm \cdot 045$ & $5.73 \pm \cdot 034$ \\
\hline 2. & $5 \cdot 94 \pm \cdot 056$ & $6 \cdot 16 \pm \cdot 065$ & $6 \cdot 15 \pm \cdot 056$ \\
\hline 3. & $6 \cdot 15 \pm \cdot 056$ & $6 \cdot 03 \pm \cdot 067$ & $6 \cdot 09 \pm \cdot 050$ \\
\hline \multicolumn{4}{|c|}{ Phosphate. } \\
\hline 1. & $10 \cdot 7 \pm \cdot 23$ & $14.5 \pm \cdot 37$ & $15 \cdot 5 \pm \cdot 33$ \\
\hline 2. & $7 \cdot 4 \pm \cdot 20$ & $10 \cdot 7 \pm \cdot 30$ & $10 \cdot 7 \pm \cdot 28$ \\
\hline 3. & $10 \cdot 3 \pm \cdot 20$ & $13 \cdot 6 \pm \cdot 33$ & $13 \cdot 9 \pm 32$ \\
\hline \multicolumn{4}{|c|}{ Non-phosphate (" organic ") Acid. } \\
\hline 1. & $11 \cdot 7 \pm \cdot 31$ & $15 \cdot 4 \pm 40$ & $17 \cdot 5 \pm \cdot 48$ \\
\hline 2. & $13 \cdot 7 \pm \cdot 46$ & $17 \cdot 3 \pm \cdot 53$ & $19 \cdot 0 \pm \cdot 60$ \\
\hline 3. & $13 \cdot 7 \pm \cdot 43$ & $16 \cdot 6 \pm \cdot 55$ & $19 \cdot 4 \pm \cdot 53$ \\
\hline \multicolumn{4}{|c|}{$\mathbf{P .}$} \\
\hline 1. & $47 \cdot 0 \pm \cdot 71$ & $47 \cdot 7 \pm \cdot 72$ & $46.8 \pm 69$ \\
\hline 2. & $37 \cdot 0 \pm \cdot 80$ & $38 \cdot 1 \pm \cdot 87$ & $36 \cdot 6 \pm 82$ \\
\hline 3. & $44 \cdot 2 \pm \cdot 69$ & $45 \cdot 0 \pm 84$ & $41 \cdot 7 \pm \cdot 77$ \\
\hline
\end{tabular}

(To economize space, the S.D. has been omitted from this table.)

Results.

Free acid.-In all three specimens the acid excretion of the rheumatic and asthmatic groups exceeds that of the normal by a significant amount but they approximate to each other closely.

Total acid.-There is the same excess excretion of acid by the asthmatic and rheumatic groups and in the first and third specimens the same close approximation of the mean. The difference in the second specimen is statistically significant, showing a greater acid excretion by the asthmatic group after the first meal.

' $\mathbf{R}$.' - $\mathbf{R}$ ' is really $\frac{\text { total acid - free acid }}{\text { free acid }}$ and indicates the manner in which the excess acid is excreted. The results do not, however, follow the same lines as the free and total means. In the first specimen the rheumatic group differs from the normal by a barely significant value and the asthmatic group approaches the normal. In the second specimen there no significant 
difference between the three groups while in the third group the normal is significantly greater than the other two groups which are almost identical.

pH.-In the first and last specimens there are no significant differences between the three groups but in the second specimen the normal is more acid than both the other groups which are almost identical. Thus, as previously noted, the normal shows the alkaline tide less well than the disease groups.

Phosphate.-In all three specimens the normal shows less phosphate than the rheumatic and asthmatic groups. It is of interest that in all the phosphate falls with the lessened acidity in the second specimen.

Non-phosphate titrateable acid.-There is a definite difference between each group, the asthma group passing more than the normal in all three specimens and the rheumatic group passing more than either. This is probably due mainly to organic acid as the bicarbonate content must vary with the $\mathrm{pH}$ and there is no correlation between the average $\mathrm{pH}$ values and the non-phosphate acid values.

P.-It is strange that with such large variations between the groups in the two factors concerned (phosphate and non-phosphate acid) the values of ' $\mathbf{P}$ ' for each group come so close to each other and at the same time show so large a difference between each specimen. It indicates that the ratio of the organic acid to the phosphorus excreted is constant in all groups at a given time of day but that the ratio varies during the day. It suggests that some factor other than the alkaline tide is partly responsible for the drop in the phosphate in the second specimen.

\section{Discussion.}

It is unfortunate that the failure to obtain an exactly similar environment for the control group makes it impossible to decide whether the increased acid output of the disease groups is due to the presence of disease or to the partaking of a more acid-forming diet. The institutional diet is stated to be well balanced and to contain an adequate amount of fruit and vegetables which would tend to diminish the acidity. It is quite likely that the disease groups would have in many cases as good a diet; again in those families where poverty prevents the consumption of the more expensive alkali-producing fruit and vegetables a similar reduction would occur in the equally expensive acid-producing proteins. It is quite probable that in the aggregate the diets of the disease groups would not be much more acid producing than the institutional diets. On the other hand a bigger range of variability in the diet consumed must occur in the disease groups than in the normal group and this is reflected in the uniformly smaller standard deviation found in the normal group.

A further support for this view is given by some figures of dietaries of rheumatic families compared with non-rheumatic families and with a residential school in which practically no rheumatism was occurring 
(Warner ${ }^{5}$ ) (table 4). The differences between the three groups is too small as to be of any significance in this investigation.

TABLE 4.

Man values of Food CONSUMed in RHeUmatic and NON-RHeumatic families aNd a POOR LAW CHILdREN'S HOME.

$\begin{array}{llcccr} & & & \text { Carbohydrate. } & \text { Protein. } & \text { Fat. } \\ \text { Rheumatic families } & \ldots & \ldots & \mathbf{4 5 0} & \mathbf{9 6 . 5} & 110 \\ \text { Non-rheumatic families } & \ldots & \mathbf{4 3 5} & \mathbf{9 0 \cdot 0} & \mathbf{1 0 9} \\ \text { Poor Law Homes } \quad \ldots & \ldots & \mathbf{4 6 0} & \mathbf{9 8 \cdot 0} & \mathbf{9 5}\end{array}$

The choice of asthma as a second disease group was made for two reasons : there was ready at hand a large clinic and secondly at that time it was postulated that an element of alkalosis entered into the asthmatic syndrome. The environmental and dietetic conditions of both groups were probably identical. The close agreement of the two groups, however, was unexpected, the main significant difference being in the organic acid output, the rheumatic group exceeding the asthmatic group. An explanation of the increased acid output of the asthmatic group was, however, forthcoming. Unknown to the author at the time of the inception of the scheme nearly all the asthmatic children were receiving $1 \frac{1}{2}$ drachms of acid. hydrochlor. dil. a day (equivalent to 145 c.c. of $\mathrm{N} / 10 \mathrm{HCl}$ ). It is not possible to computate at all closely the actual effect of this acid in the ratios, but calculation gives a value between 7-13 as a fair deduction to be made from the total acid ratio. This is of the same magnitude as the difference between the normal and the asthma group. A few cases were found in which no acid had been given and in these the values tended towards the normal group. The number was insufficient for statistical treatment. This approximation of the asthma control group to the normal strengthens the conviction that the dietetic and environmental conditions are not sufficiently different to invalidate the results.

The values for ' $\mathbf{R}$ ' show some points of interest. Studies of artificially induced acidosis ${ }^{6,7}$ show that the ammonia production lags behind the acid excretion giving a low value for ' $R$ ' at first. The ammonia output then increases giving an increasing value for ' $R$.' On the cessation of the induction of acidosis the acid output returns rapidly to normal, but the return of the ammonia to normal is delayed giving again a high value for ' $\mathbf{R}$.' The high values for ' $\mathbf{R}$ ' in the second specimen do not indicate an acidosis but are due to the cessation of the acid output of the overnight period with the morning alkaline tide. The higher values of ' $\mathbf{R}$ ' in the normal group must be due also to a greater readiness to produce ammonia on the part of the organism since the actual acid excretion is less.

The difference in the values for phosphate between the normal and the disease groups could be accounted for in several ways. The phosphate content of the normal group diet might be less-this is not likely. The absorption of phosphate from the gut is inhibited by excess of calcium or by an increased alkalinity of the gut contents. This again is unlikely since it places the healthy group at a disadvantage in regard to calcium 
and phosphorus absorption. Finally, since phosphates are used by the kidney as a means of excreting acid an increased acid output calls forth an increased phosphate output. There is no lag in the phosphate-acid excretion mechanism such as there is with ammonia and this is exemplified in the fall of phosphate in the second specimen with the alkaline tide. This is shown equally well in all groups. It is probable, therefore, that the cause of the difference lies mainly with the increased acid output.

It is not surprising that no significant differences have been found in the blood acid-base equilibrium since the extra acid is excreted without even altering the $\mathrm{pH}$ or the ammonia-acid ratio (' $R$ ').

The extra acid is doubtless removed without any straining of the normal mechanism-the increase in the ammonia and the decrease in the $\mathrm{pH}$ (i.e. increase in acidity) are well known signs of acidosis, and both these are absent.

\section{Conclusions.}

From the above results it may be reasonably concluded that the rheumatic child in a quiescent interval excretes more acid in its urine than does either an asthmatic or a normal child. Part of this excess of acid is due to organic acids. This excess production of acid is insufficient to disturb the equilibrium of the blood. No further conclusions bearing on rheumatism can be made but it may be suggested that there is some truth in the ' acid diathesis' theory of rheumatism.

\section{Summary}

The urinary output of the three groups of children, rheumatic, asthmatic and normal has been examined and compared statistically in respect of the free, total and organic acid and phosphate content and also the $\mathrm{pH}$. Allowing for the acid therapy in the asthma group it has been shown that the rheumatic group excreted more acid than the other groups but there was no alteration in the $\mathrm{pH}$ of the urine.

My thanks are due to the physicians to out-patients at the Hospital for Sick Children, Great Ormond Street, for permission to examine their cases and to Dr. Bray, who was supervising the Asthma Clinic at the time. I am greatly indebted to Mr. S. Hattersley, the Superintendent of Banstead Residential School, for the collection of the urines from the 200 normal children.

The expenses of this investigation were defrayed by a grant from the Medical Research Council.

\section{REFERENCES.}

1. Parsons, L. G., \& Edgar, S. H., Arch. Dis. Child., Lond., 1929, IV, 291.

2. Henderson, L. J., \& Palmer, W. W., Arch. Int. Med., Chicago, 1915, XVI, 100.

3. Benedict, S. R., \& Nash, T. P., J. Biol. Chem., Baltimore, 1929, LXXXII, 673.

4. Fisher, R. A., Statistical Methods for Research Workers, Edinburgh, 1932.

5. Warner, E. C., Personal communication.

6. Morris, N., \& McRae, O., Arch. Dis. Child., London, 1930, V, 207.

\%. Payne, W. W., Unpublished observations. 